\title{
La izquierda en América Latina
}

\section{The left in Latin America}

\section{LUDOLFO PARAMIO}

Profesor de investigación del CSIC y director del programa de América Latina del Instituto Universitario de Investigación Ortega y Gasset.

RESUMEN

La frustración de las expectativas creadas por las reformas estructurales, tras la nueva crisis de finales de los años noventa, ha llevado al electorado en muchos países a castigar a los partidos que se habían identificado con ellas. En algunos casos, un descrédito generalizado de los partidos anceriores ha conducido a la aparición de liderazgos "populistas". Pero, con pocas excepciones, el problema de la izquierda latinoamericana sigue siendo la dificulad de crear partidos con identidades políicas duraderas.

Palabras clave: izquierda, América Lacina, partidos políricos, crisis de represencación, populismo.

ABSTRACT

High expectations in the results of structural reform were frustrated by a new economic crisis in the late nineties. Voters have punished governments identified with the Washington Consensus and its poor results, and, when old political parties suffered a generalized discredit, this has given rise to a "new populism". With few exceptions, however, the central problem of the Latin American left is its unability to build political parties with a defined political profile and able to endure.

Key words: left, Latin America, political parties, crisis of representacion, populism. 


\section{BÚSQUEDA Y DESORIENTACIÓN}

Desde los años ochenta la izquierda se ha encontrado en todo el mundo en un terreno nuevo, porque sus estrategias políticas estaban diseñadas para aglutinar a las mayorías populares, trabajadores y clases medias, mediante políticas que sólo podían ser plenamente eficaces en el marco de economías cerradas, impulsando la demanda desde el Estado y contando con que la inversión privada vendría después. Pero las condiciones para el éxito de esas políticas habían dejado de existir.

Los reveses económicos de la Unidad Popular en Chile (1971-73) y de la primera fase del gobierno socialista francés (1981-83) mostraron, independientemente de sus muy distintos efectos políticos, que las políticas de gestión de la demanda encontraban pronto límites en economías dependientes o abiertas. El contexto crecientemente globalizado de la economía mundial hizo cada vez más patente el agotamiento de las estrategias tradicionales.

Desde entonces cobraron nueva vida las viejas polémicas sobre los rasgos definitorios de la izquierda y sobre la hipotética convergencia de izquierda y derecha en un terreno común o intermedio de pragmatismo económico. Es posible que estas polémicas tengan sentido, pero cabe pensar que sólo se producen cuando la izquierda o la derecha modifican sus anteriores planteamientos para adaptarse a una situación nueva.

En la Europa de posguerra, las políticas de bienestar fueron abrazadas por la derecha tanto como por la izquierda, y los conservadores reclamaban incluso que aquéllas habian sido introducidas por vez primera por algunos de sus grandes líderes, aunque sin recordar que lo hicieron con el propósito de deslegitimar o mantener proscritas a las organizaciones obreras de izquierda. Y luego, en 1971, Richard Nixon dijo aquello de que "ahora todos somos keynesianos".

Se podía pensar entonces que el llamado consenso keynesiano reflejaba una convergencia de la derecha hacia las posiciones de la izquierda. Pero el final de la era de Bretton Woods obligó a la izquierda a buscar nuevas estrategias para adaptarse a un mundo en el que ya no funcionaban las políticas keynesianas, $y$ esa búsqueda permitió que renaciera la idea de una convergencia entre izquierda y derecha. El problema, sin embargo, era que esa polémica en parte expresaba una profunda desorientación de los electores ante los giros estratégicos de los partidos de izquierda.

A la hora de decidir su voto, las personas emiten un juicio de confianza - mayor o menor- hacia un partido concreto. Esta confianza puede reflejar una identificación con ese partido o un simple cálculo sobre lo que cabe esperar de él si forma gobierno, en relación con los intereses particulares del elector o con lo que éste entiende que son los intereses colectivos del país. En ambos aspectos, identificación o cálculo, un giro estratégico del partido significa un factor de desorientación para el elector.

En efecto, la identificación, independientemente de los mecanismos sociales a través de los cuales se desarrolle, implica una valoración de la trayectoria de ese partido. Un cambio de estrategia implica un cambio de 
trayectoria, y en ese sentido pone en peligro la anterior identificación. Pero el cálculo también se basa en la trayectoria anterior: no es posible calcular cuál será el impacto — sobre los intereses personales o colectivos- de un gobierno si ya no cabe prever cuáles serán sus políticas.

En otras palabras, los giros de los partidos de izquierda para gobernar en el nuevo contexto económico desde los años ochenta han causado una desorientación mayor o menor de sus electores y del electorado en general. Pero, además, las nuevas reglas de la economía y los cambios sociales anteriores han creado un mapa social distinto en el que muchos grupos se sienten carentes de representación política. Porque sus partidos de siempre han cambiado o porque se trata de grupos en los que ningún partido parece pensar.

\section{CRISIS DE REPRESENTACIÓN}

El resultado, bastante perceptible en muchos países de América Latina, es la aparición de una crisis de representación, de una envergadura similar a la que se produjo en los años treinta a consecuencia de los cambios producidos primero por el desarrollo exportador y luego por la crisis de 1929. La comparación resulta especialmente sugestiva porque ambas coyunturas se caracterizan por la aparición de liderazgos populistas, en el sentido de personalistas y con un discurso agresivo contra los partidos políticos anteriores.

Para situar mejor este fenómeno puede ser útil recordar la secuencia que lleva de la crisis de la deuda, en los años ochenta, a la actual fase de crecimiento económico, desde finales de 2002. Independientemente de las primeras interpretaciones de la crisis, a finales de los años ochenta se había extendido la percepción de que se trataba de una crisis estructural, que exigía un drástico cambio en la actuación económica del Estado, y en particular una reducción del crónico déficit público, entendido ahora como déficit estructural.

En ese contexto se extendió el llamado Consenso de Washington y se llevaron a cabo en los primeros años noventa en buena parte de América Latina las llamadas reformas estructurales, activamente impulsadas por el Fondo Monetario Internacional y los distintos organismos financieros multilaterales. Aquella agenda de reformas era discutible en muchos aspectos, pero probablemente se puede afirmar que sin emprenderlas no era posible para los países de la región obtener la financiación, pública y privada, necesaria para volver a crecer, ya que los inversores no confiarían en los países que no las realizaran.

En países con bajas tasas de ahorro y asfixiados por la deuda, resultaba imprescindible la financiación exterior. No es posible generalizar, ya que la capacidad exportadora de Brasil, por ejemplo, creaba unas condiciones distintas, pero la necesidad de obtener financiación y de cortar los procesos hiperinflacionarios explica en buena medida la aceptación de la agenda de las reformas estructurales. Los gobiernos no tenían otra alternativa que llevarlas a cabo para obtener la confianza de los mercados.

Las inversiones traídas por la ola de privatizaciones, y la nueva estabilidad macroeconómica impulsaron una fase de crecimiento 
regional que se vería cortado por un choque externo, el impacto de la crisis asiática de 1997. Desde 1998 hasta finales de 2002, y pese a un repunte del crecimiento en 2000 , se extendió por la región un clima de frustración, ante la promesa incumplida de que las reformas estructurales iban a traer un crecimiento estable y sin nuevas crisis.

Ese sentimiento de frustración era ya patente en Venezuela en 1998, pues el gobierno de Rafael Caldera no había satisfecho las expectativas sociales, y la crisis de los dos partidos tradicionales llevó a la presidencia en 1999 a Hugo Chávez. En enero de 2000 Lucio Gutiérrez encabezó una efímera junta en Ecuador, preámbulo de su victoria electoral en 2003, como Chávez se había beneficiado de su intento de golpe en 1992 contra el «neoliberalismo" de Carlos Andrés Pérez.

En diciembre de 2001 se produjo el colapso de la convertibilidad argentina, que había pasado de ser una garantía de estabilidad y crecimiento a convertirse en un corsé asfixiante de la economía nacional. Con la convertibilidad cayó el gobierno de Fernando de la Rúa, que a su vez arrastró a una completa pérdida de credibilidad a la UCR y al Frepaso que le habían apoyado. En mayo de 2003 resultó elegido Néstor Kirchner. Ese mismo año, en octubre, el presidente boliviano Gonzalo Sánchez de Lozada abandonó el país y fue sustituido por el vicepresidente Carlos Mesa, en medio de una situación de creciente ingobernabilidad que llevaría a la victoria arrolladora de Evo Morales en diciembre de 2005.

No resulta muy arriesgado vincular estas turbulencias a la frustración de las expec- tativas que habían creado las reformas estructurales. Aunque el peor coste social de las reformas ya se había absorbido en parte, el sentimiento de que se había pagado un alto precio sin resolver los problemas sociales se fue extendiendo en amplias capas, incluyendo las clases medias. Era casi inevitable que brotara una profunda agresividad contra los gobernantes y los partidos que habían impulsado las reformas o que, simplemente, habían tenido la desgracia de estar en el poder después de 1998, cuando se vieron incumplidas las promesas de las reformas.

\section{¿DOS IZQUIERDAS?}

Como es sabido, en pocos países de América Latina existen opciones partidarias que se puedan identificar como de izquierda según los modelos y tradiciones europeas: se podría decir que sólo en el espectro político chileno. Sin embargo la rebelión contra los partidos preexistentes ha llevado a hablar de la aparición de dos tipos de izquierda en América Latina.

Por un lado tendríamos partidos como el PS y el PPD chilenos, el Frente Amplio uruguayo y el PT brasileño, que impulsan una agenda política de centro-izquierda. Y por otro partidos de reciente creación, como el MAS boliviano, el nuevo PSUV que pretende aglutinar el apoyo político a Chávez en Venezuela, el movimiento PAIS de Rafael Correa en Ecuador o el Partido Nacionalista Peruano de Ollanta Humala, que representan una marcada opción de ruptura, y a los que a menudo se encuadra como representantes de un "nuevo populismo". 
Esta dicotomía deja fuera, sin embargo, gran parte del mapa político de la izquierda. No sólo partidos herederos de la izquierda radical de los años setenta, como el FMLN salvadoreño o el Polo Democrático Alternativo en Colombia, sino también partidos que tradicionalmente se podian considerar populistas, como el peronismo argentino, que actualmente desarrolla políticas próximas al centro-izquierda, pero manteniendo un discurso populista (o nacional-popular) y una dinámica de gobierno que le aproxima al nuevo populismo.

La pregunta que cabe hacerse, a la vista de la coyuntura actual, es si el nuevo populismo define una tendencia histórica o es un fenómeno fechado, arraigado en unas circunstancias muy específicas. En primer lugar, es evidente que la aparición de liderazgos populistas sólo se ha producido hasta ahora en países en los que previamente se había producido el colapso del sisrema de partidos, con una pérdida de credibilidad simultánea de los partidos preexistentes.

En segundo lugar, y aunque pueda parecer paradójico, una condición para la extensión del nuevo populismo parece haber sido la percepción social de que el alza de los precios de los hidrocarburos y de las exportaciones primarias permitía a los gobiernos hacer una política de redistribución a la vieja usanza, y alejarse de las reglas del Consenso de Washington. Para entender este segundo punto basta recordar las dos etapas de la presidencia de Chávez, antes y después del efímero golpe de 2002 y de la posterior huelga de PDVSA.

En la primera fase, pese a la dinámica de movilización política impulsada por Chávez, sus apoyos se debilitaron por la ausencia de resultados económicos. Fue la subida de los precios del petróleo, y de los ingresos por su exportación, lo que permitió el reasentamiento de esos apoyos en una situación de fuerte polarización política. Dicho de orra forma: lo que ha caracterizado políticamente al nuevo populismo es esa dinámica de polarización, pero lo que le ha permitido consolidarse, y extenderse de Venezuela a otros países, ha sido el auge de los precios de los hidrocarburos y de las materias primas en el mercado mundial.

Esto podría significar que el futuro de los nuevos populismos depende de la continuidad de ese auge, que en estos momentos (septiembre de 2008) no está asegurado. Un hipotético estancamiento de la economía global, incluso si China e India continúan creciendo, traería un entorno desfavorable para unos gobiernos cuya principal apuesta es redistribuir los ingresos de las exportaciones, y que sufren no sólo fuertes tensiones inflacionarias sino situaciones de desabastecimiento interno en parte como consecuencia de sus deseos de controlar los precios.

Esa dependencia del mercado global es probablemente la principal debilidad de gobiernos cuyo discurso incluye de forma explícita el rechazo de las reglas "neoliberales" del mercado. Pero quizá es inevitable una vez que su dinámica de polarización política les enfrenta con los sectores empresariales internos y desincentiva la inversión. La gran pregunta es si existen alternativas a esa polarización.

Quizá el gobierno de Evo Morales sea un buen ejemplo del problema. Los movimientos y grupos sociales con presencia local y 
sectorial que le apoyan no habían desarrollado una mediación política común antes de su triunfo electoral de 2005. Lo que les une es el rechazo del "régimen neoliberal», y por ello coinciden en la confrontación y se dividen ante cualquier posible concesión. Dado que sin concesiones mutuas es casi imposible una negociación con éxito, sólo se ha llegado a hablar de acuerdo con la oposición después de que las tensiones hayan alcanzado el límite de la violencia.

Más en general, en la medida en que el ascenso del "nuevo populismo» es la expresión de la agresividad de los ciudadanos contra los partidos políticos anteriores, a los que consideran culpables de la frustración de sus expectativas o incapaces para asumir sus problemas, el nuevo gobernante tiene todos los incentivos para mantener una polarización que refuerce esos sentimientos, y ninguno para negociar acuerdos que puedan ser vistos como una traición a los intereses populares.

Eso significa una gran dificultad para llegar a reglas de juego aceptables —objetiva y no sólo subjetivamente - para los sectores empresariales y las clases medias, y una fuerte tentación para reemplazarlos desde un nuevo y ampliado sector de economía estatal o social. El riesgo de que esto lleve a la desinversión y al retroceso económico es muy grande, y el nuevo sector público puede ser poco competitivo a la larga y depender exclusivamente de los ingresos por exportaciones de hidrocarburos.

Una pregunta inevitable, entonces, es la de si el nuevo populismo podrá sobrevivir a una caída de los precios de los hidrocarburos y otras materias primas. La respuesta puede estar ligada a la cuestión central al analizar la historia, la situación actual y las perspectivas de la izquierda en América Latina: sus dificultades para crear partidos políticos con un perfil ideológico definido y con una identidad duradera en el tiempo.

\section{¿PERSONALIDADES O PARTIDOS?}

En estos momentos se diría que el problema de la creación y consolidación de partidos de izquierda resulta especialmente difícil de resolver, dado que el ascenso de los medios audiovisuales ha llevado a una fuerte personalización de la política. Hoy más que nunca los ciudadanos eligen entre personas, no entre programas o partidos. La proximidad a los candidatos que permite la televisión deja muy en segundo plano a las organizaciones que los apoyan, y sólo permite discutir sus propuestas a partir de enunciados muy generales y a menudo imprecisos.

No es evidente que tenga que ser así, como si la televisión condujera inevitablemente al empobrecimiento del debate político. Pero la forma en que actualmente se desarrollan las campańas conduce casi inevitablemente a este resultado: se seleccionan los mensajes por su impacto mediático, no para ejemplificar políticas públicas concretas o resumir la coherencia de un programa. La escasez (o simple ausencia) de debates entre los candidatos favorece la demagogia y la banalización del discurso.

Además, la inexistencia de financiación pública de las campañas —que permitiría imponer reglas sobre su desarrollo-, no sólo 
permite esta trivialización, sino que crea mecanismos perversos de vinculación entre los candidatos y las personas y grupos que poseen recursos financieros, lo que siempre es malo para la independencia de los políticos democráticos, pero puede ser peor si las fuentes de esos recursos son ilegales: hay ya demasiados casos de la llamada narcopolítica.

Más allá de los cambios que serían necesarios para evitar que la comunicación política a través de los medios produzca un empobrecimiento del debate político, lo que parece poco discutible es que en la actualidad es mucho más fácil crear un partido político a partir de un candidato que posea una cierta popularidad o una personalidad atractiva. Y no se trata de una cuestión de fotogenia, como revelan claramente algunos casos del nuevo populismo.

Pero, a la vez, es mucho más difícil que ese partido se institucionalice hasta el punto de ofrecer un perfil político propio, capaz de crear lealtades duraderas más allá de candidatos o dirigentes particulares. Las siglas políticas son hoy un producto perecedero y secundario, como entendió muy bien el presidente Fujimori al crear partidos políticos nuevos a su servicio para cada elección. $\mathrm{El}$ contraste con un partido con arraigo social y estructura organizada, como el APRA, es bastante revelador.

La fungibilidad de los partidos políticos presenta graves problemas para el funcionamiento de la democracia. El primero y muy evidente es que, si un partido sirve sólo para un proceso electoral, los electores no tienen a quién castigar con su voto en el siguiente proceso si su actuación ha resultado desastrosa. El segundo es que la fuerza de las personalidades y la debilidad de las siglas conduce casi inevitablemente al "reeleccionismo" en el caso de presidentes que terminan su mandato con alta popularidad, ya que a la preferencia de los gobernantes por permanecer se suma la incertidumbre de sus seguidores sobre los resultados de unas elecciones sin el candidato al que los electores han apoyado y apoyan.

Pero hay un problema mayor. Excepto en los casos de reelección, la discontinuidad o simple debilidad de las siglas partidarias provoca en cada convocatoria electoral un comienzo desde cero de las políticas públicas, políticas cuya eficacia depende muy a menudo precisamente de su continuidad, del carácter gradualmente acumulativo de sus resultados. Unos partidos políticos volátiles conducen casi inevitablemente a unas políticas públicas improvisadas y sin continuidad, excepto cuando los condicionamientos externos obligan a mantenerlas aunque por razones electorales se hayan denunciado las del gobierno anterior, como frecuentemente sucede con la gestión macroeconómica ortodoxa.

\section{PERSONALISMO O INSTITUCIONES}

A todos estos inconvenientes de la personalización de la política se suma el que resulta central para los propósitos de esta nota: es mucho más fácil crear nuevos partidos ${ }^{\mathrm{I}}$ que mantenerlos con un perfil político duradero. Esto atañe también a las fuerzas del «nuevo populismon: si sus líderes se desgastan o pierden el gobierno es difícil imaginar la continuidad 
de sus actuales organizaciones de apoyo, especialmente si éstas son una coalición laxa de movimientos y colectivos sociales.

El problema tiene al menos dos dimensiones. La primera es que los liderazgos personales fuertes no intentan normalmente institucionalizar sus bases de apoyo, en parte por pensar que su carisma no puede "rutinizarse", en la expresión de Weber, $y$ en parte porque en un partido institucionalizado es más verosímil la rebelión contra el líder y su desplazamiento. Sea por una concepción mística del propio liderazgo, sea por deseo de mantener el poder, es infrecuente el caso de líderes "carismáticos» que se proponen crear un partido fuerte. En este sentido llama la atención el caso de Chávez y su intento de pasar del Movimiento V República a un Partido Socialista Unido de Venezuela. La clave es probablemente el deseo de seguir el modelo cubano, pero también un cálculo -que podría resultar equivocado- para cortar la indisciplina entre sus apoyos y seguidores iniciales.

Con la habitual excepción de Chile, donde los partidos de izquierda han mantenido desde los años treinta perfiles ideológicos definidos - lo que les ha exigido un laborioso proceso de «renovación" para adaptarse a los cambios sociales-, los dos grandes partidos de izquierda en la región que han llegado al gobierno son el PT brasileño y el Frente Amplio uruguayo, por más que éste sea una coalición de partidos. ¿Cabe imaginar un proceso de creación de nuevos partidos con posibilidades de llegar al poder?
A la vista de los ejemplos citados, se podría pensar que el primer factor para ello es que no se produzca un exito demasiado rápido: un largo tiempo en la oposición puede ser la clave para llegar a una cierta coherencia interna. Pero los dos ejemplos muestran también la importancia de un liderazgo claro que asegure la cohesión del partido. Las dificultades para definir ese liderazgo pueden ser mayores incluso que las derivadas de una previa heterogeneidad ideológica: diferentes culturas pueden coexistir en una misma organización en la medida en que se reconocen en un mismo liderazgo.

Esta es la contradicción entre las dos exigencias fundamentales para la construcción de una nueva fuerza de izquierda. Por una parte la dinámica electoral y política favorece el personalismo, y éste tiende a dejar en segundo plano el desarrollo organizativo, institucional y programático de un verdadero partido polícico. Pero, por otra parte, es poco probable que una fuerza política atraviese el necesario proceso de maduración — sin disgregarse o perder toda credibilidad- en ausencia de un liderazgo interno reconocido.

El descrédito de la política institucionalizada, la personalización de la política y el riesgo de trivialización del debate político son hechos propios de nuestro tiempo. Pero en cambio no es nueva la necesidad de contar con un liderazgo claro y a la vez desarrollar un largo trabajo de organización. Lo difícil es hacerlo en tiempos de impaciencia y de volatilidad electoral. 
1. Hay excepciones: la legislación mexicana dificulta la entrada de nuevos partidos en el sistema, pero los que lo logran consiguen perpetuarse mediante acuerdos con los partidos tradicionales, lo que reduce considerablemente la competitividad efectiva y favorece el desdibujamiento programático.

\section{BIBLIOGRAFÍA}

Acevedo, María Luisa, Educación interétnica, México, Instituto Nacional de Antropología e Historia (INAH), Edición Científica, 1996.

Avifa, Ortiz Raúl (2000), El Derecho Cultural en México: una propuesta académica para el proyecto politico de la modemidad, México, Miguel Ángel Porrúa Aguirre, Gonzalo, El proceso de aculturación, México, Centro de Investigaciones y Esrudios Superiores en Antropología Social (CIESAS), Ediciones la Casa Chata, 1982.

Banco Mundial, *Directriz Operacional (OD 4.20)", en Mantaal Operacional del Banco Mundial, septiembre de 1991, Washington.

Caso, Alfonso et al., La politica indigenista en México. Métodos y resultados, 2a. edición, tomo I, México, Colección SEP-INI, Núm. 20, Serie de Antropología Social, 1973.

Cepal, Instituciones y organizaciones de productores rurales: experiencias de interés para Centroamérica, México, 1997.
Ciesas e INI, Histaria de los pueblos indigenas de México, tomos: I-VI, México, 1994.

Díaz Polanco, Héctor, Autonomía regional. La autodeterminación de los pueblos indios, México, Siglo XXI y Universidad Nacional Autónoma de México (UNAM), 1991.

Naciones Unidas, Consejo Económico y Social, Estudio del problema de la discriminación contra las poblaciones indigenas, Informe final que presenta el Relator Especial señor José R. Martínez Cobo, Comisión de Derechos Humanos, $34 .^{\circ}$ período de sesiones, 1981.

Ordóñez Cifuentes, José Emilio, Reclamos jurídicos de los pueblos indios, México, UNAM, 1993.

Villoro, Luis. "Los Derechos Humanos de los Pueblos". Fascículo 1. Los Derechos de los Pueblos Indigenas. Comisión Nacional de los Derechos Humanos. México, 2003. p. 98. 